\title{
Co-morbidity of progressive supranuclear palsy and amyotrophic lateral sclerosis: a clinical-pathological case report
}

Koji Fujita ${ }^{1 \dagger}$, Tomoyasu Matsubara $^{2 \dagger}$, Ryosuke Miyamoto ${ }^{1}$, Hiroyuki Sumikura ${ }^{2}$, Toshiaki Takeuchi ${ }^{1}$, Keiko Maruyama Saladini ${ }^{1,3}$, Toshitaka Kawarai ${ }^{1}$, Hiroyuki Nodera ${ }^{1}$, Fukashi Udaka ${ }^{4}$, Kodai Kume ${ }^{5}$, Hiroyuki Morino ${ }^{5}$, Hideshi Kawakami ${ }^{5}$, Masato Hasegawa ${ }^{6}$, Ryuji Kaji ${ }^{1}$, Shigeo Murayama ${ }^{2}$ and Yuishin Izumi ${ }^{{ }^{*}}$ (D)

\begin{abstract}
Background: The coexistence of distinct neurodegenerative diseases in single cases has recently attracted greater attention. The phenotypic co-occurrence of progressive supranuclear palsy (PSP) and amyotrophic lateral sclerosis (ALS) has been documented in several cases. That said, the clinicopathological comorbidity of these two diseases has not been demonstrated.

Case presentation: A 77-year-old man presented with gait disturbance for 2 years, consistent with PSP with progressive gait freezing. At 79 years old, he developed muscle weakness compatible with ALS. The disease duration was 5 years after the onset of PSP and 5 months after the onset of ALS. Neuropathological findings demonstrated the coexistence of PSP and ALS. Immunohistochemical examination confirmed 4-repeat tauopathy, including globose-type neurofibrillary tangles, tufted astrocytes, and oligodendroglial coiled bodies as well as TAR DNA-binding protein $43 \mathrm{kDa}$ pathology in association with upper and lower motor neuron degeneration. Immunoblotting showed hyperphosphorylated full-length 4-repeat tau bands (64 and $68 \mathrm{kDa}$ ) and C-terminal fragments ( $33 \mathrm{kDa}$ ), supporting the diagnosis of PSP and excluding other parkinsonian disorders, such as corticobasal degeneration. Genetic studies showed no abnormalities in genes currently known to be related to ALS or PSP.
\end{abstract}

Conclusions: Our case demonstrates the clinicopathological comorbidity of PSP and ALS in a sporadic patient. The possibility of multiple proteinopathies should be considered when distinct symptoms develop during the disease course.

Keywords: Amyotrophic lateral sclerosis, Progressive supranuclear palsy, TAR DNA-binding protein 43 kDa (TDP-43), Tau, Copathology

\section{Background}

Progressive supranuclear palsy (PSP) was originally described as involving dystonic posturing of the neck and axial rigidity, vertical supranuclear gaze palsy, postural instability, gait disturbance with an ataxic quality, early falls, dysarthria, dysphagia, and a poor levodopa response [1]. PSP is neuropathologically characterized by extensive degeneration of the globus pallidus, subthalamic nucleus, substantia nigra, and pons as well as 4-repeat tau

\footnotetext{
* Correspondence: yizumi@tokushima-u.ac.jp

${ }^{\dagger}$ Koji Fujita and Tomoyasu Matsubara contributed equally to this work.

${ }^{\dagger}$ Koji Fujita and Tomoyasu Matsubara are co-first authors

'Department of Neurology, Tokushima University Graduate School of

Biomedical Sciences, 3-18-15 Kuramoto-cho, Tokushima 770-8503, Japan Full list of author information is available at the end of the article
}

accumulation in both neurons and glia [2, 3]. Broad clinical phenotypes of PSP have been reported, including Richardson's syndrome, progressive gait freezing, corticobasal syndrome, and primary lateral sclerosis (PLS) [4]. The PSP-PLS phenotype presents with upper motor neuron involvement and isolated tau pathology without TAR DNA-binding protein $43 \mathrm{kDa}$ (TDP-43) pathology $[5,6]$. In contrast, amyotrophic lateral sclerosis (ALS) is not regarded as a phenotype of PSP.

The co-occurrence of PSP and ALS has recently attracted greater attention. The phenotypic coexistence of PSP and ALS has been documented in several cases [7-9]. Cases of ALS plus PSP-like syndrome due only to TDP-43 proteinopathy have also been reported [10].

(C) The Author(s). 2019 Open Access This article is distributed under the terms of the Creative Commons Attribution 4.0 International License (http://creativecommons.org/licenses/by/4.0/), which permits unrestricted use, distribution, and 
These reports, however, fell short of demonstrating neuropathology to begin with or dual neuropathologies. Some PSP cases have accompanying TDP-43 pathology in the limbic system and PSP-vulnerable regions, such as the subthalamic nucleus, substantia nigra, and pontine tegmentum, but not in the motor neuron system [11]. Thus, the neuropathological co-occurrence of ALS and PSP has not been demonstrated. Here, we report a unique case in which the coexistence of PSP and ALS was demonstrated both clinically and pathologically.

\section{Case presentation}

A 77-year-old man visited our hospital due to shortstepped gait and falls, which started two years before. He had a past history of herniated lumber disc, cataract, and benign prostatic hyperplasia. His family history was unremarkable. Neurological examination revealed bradykinesia, mildly reduced arm swing on the right when walking, and retropulsion. He did not present eye movement abnormalities, resting or postural tremors, apparent rigidity, or signs of autonomic impairment. Brain MRI revealed mild frontal lobe atrophy and mild right-dominant subdural hygroma (Fig. 1a). Levodopa/ carbidopa hydrate was started but discontinued shortly due to side effects.

Nine months later, he was referred to us again due to forgetfulness and progressive gait disturbance. Neurological examination demonstrated scores of 26 and 16 in the Mini-Mental State Examination and Hasegawa Dementia Scale-Revised respectively, normal ocular and tongue movements and limb muscular strength, a positive snout reflex, a normal jaw jerk, increased tendon reflexes in the extremities, normal plantar response, short-stepped gait (especially on turning), retropulsion, and subsequent freezing of gait. Dysphagia, tremors, and rigidity were absent; muscular atrophy, fasciculation, and Hoffmann sign were not documented. A combination of amantadine, pramipexole, and levodopa/carbidopa hydrate, which was resumed, was partially effective for gait disturbance, but he still had falls and reported difficulty in writing. His body weight decreased from $64 \mathrm{~kg}$ to $42 \mathrm{~kg}$ in approximately one year. A follow-up MRI showed increased subdural hygroma and atrophy in the midbrain tegmentum (Fig. 1b).

Thirteen months after the second visit, when he was 79 years old, left- and proximal-dominant arm weakness was noted. A brain computed tomography revealed subdural hematoma predominantly on the left (Additional file 1). He was admitted to our hospital and underwent a burr-hole evacuation for the hematoma. Bilateral arm weakness and dysarthria progressed after the surgery. Neurological re-examination showed hypophonic dysarthria (which was not spastic), prominent muscle weakness in the shoulder girdle and upper limbs (manual muscle testing: deltoid $1 / 0$, biceps $2 / 2$, triceps $2 / 2$, wrist
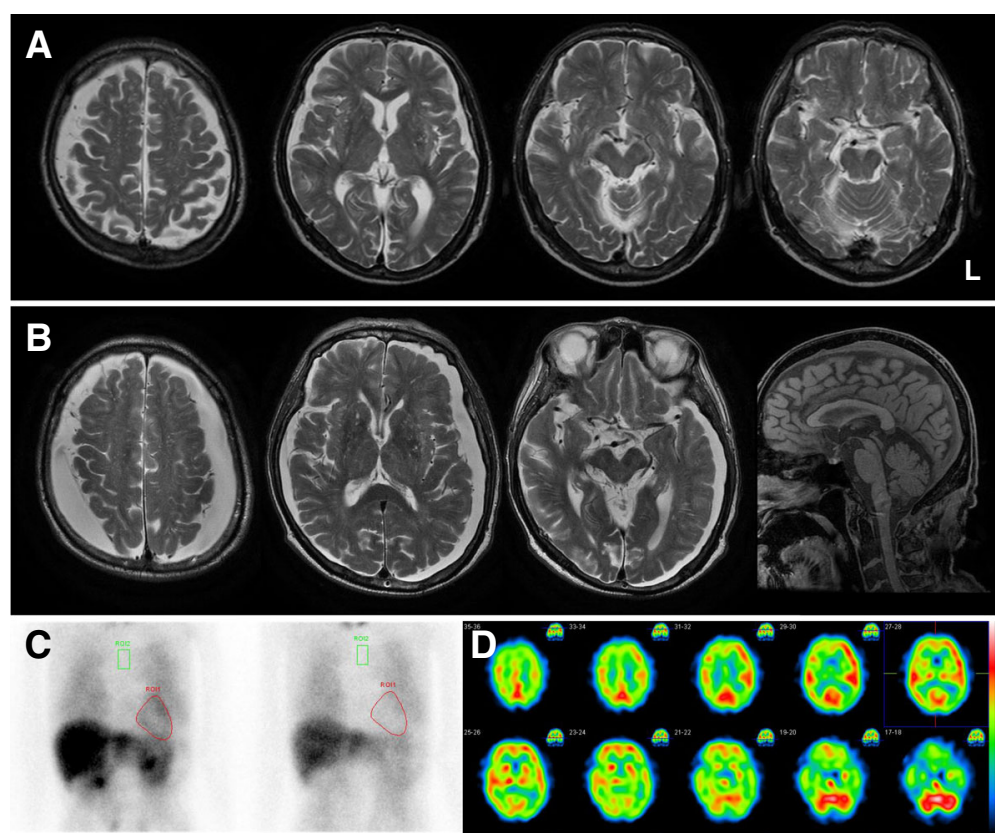

Fig. 1 Imaging findings. a A brain MRI performed at 77 years old revealed mild frontal lobe atrophy and mild right-dominant subdural hygroma. b A follow-up MRI performed at 79 years old showed increased subdural hygroma and atrophy in the midbrain tegmentum. c Cardiac ${ }^{123}$-metaiodobenzylguanidine scintigraphy showed decreased uptake in the delayed phase, suggesting mild sympathetic denervation. $\mathbf{d}$ Brain $\mathrm{N}$-isopropyl$\mathrm{p}-\left[{ }^{123}\right]$ iodoamphetamine scintigraphy showed hypoperfusion in the bilateral frontal, parietal, and occipital lobes but not the basal ganglia, thalamus, and cerebellum 
flexor $5 / 5$, wrist extensor $4-/ 2$, and finger extensor $4 / 4-$ ) but not the lower limbs (5/5), mild rigidity in the limbs (without spasticity), an increased jaw reflex, Hoffmann sign on the right, and equivocal plantar response bilaterally. Tendon reflexes were decreased in the left upper limb, mildly increased in the left lower limb, and otherwise normal. He had no restricted eye movement, dysphagia, tongue atrophy, apparent fasciculation, nuchal rigidity, or sensory disturbances. An electrophysiological study demonstrated active and chronic denervation with profound fasciculation potentials in the muscles of the brainstem, cervical, thoracic, and lumbar regions, fulfilling the definition of lower motor neuron dysfunction according to the updated Awaji criteria [12]. An ultrasonographic study revealed atrophy in the left cervical nerve roots and the left ulnar nerve and fasciculation in the upper and lower limbs. On respiratory function test (which was a poor study), \%VC was 13.2 and $\mathrm{FEV}_{1} \%$ was 152.3. An arterial blood gas demonstrated $\mathrm{pH} 7.458$, $\mathrm{PaCO}_{2} 46.7 \mathrm{mmHg}, \mathrm{PaO}_{2} 82.9 \mathrm{mmHg}, \mathrm{HCO}_{3} 32.3 \mathrm{mEq} / \mathrm{L}$, and $\mathrm{SaO}_{2}$ 96.3\%. Cardiac ${ }^{123}$ I-meta-iodobenzylguanidine scintigraphy showed decreased uptake in the delayed phase, suggesting mild sympathetic denervation. Brain Nisopropyl-p- $\left[{ }^{123} \mathrm{I}\right]$ iodoamphetamine scintigraphy showed hypoperfusion in the bilateral frontal, parietal, and occipital lobes but not the basal ganglia, thalamus, and cerebellum. He was diagnosed with clinically probable ALS according to the revised El Escorial and updated Awaji criteria, and riluzole was introduced. The score of ALS
Functional Rating Scale-Revised was 27. $\mathrm{CO}_{2}$ retention worsened quickly, and dysphagia became apparent, requiring nasogastric tube nutrition. Due to the worsening of $\mathrm{CO}_{2}$ narcosis with aspiration pneumonia, he died at age 80 years old, five months after the development of muscle weakness.

We performed a genetic analysis that included wholeexome sequencing, and the results demonstrated that there was no pathological variation in genes currently known to be associated with PSP or ALS, including $M A P T$ and GRN. No hexanucleotide repeat expansion was detected in C9orf72. The number of CAG repeats in the ATXN2 gene was 25/25 (normal).

\section{Neuropathological findings}

The brain weight was $1,240 \mathrm{~g}$. Macroscopic examination revealed selective atrophy of the anterior cervical nerve roots as well as mild atrophy of the precentral gyrus (Fig. 2a). In sections, depigmentation of the substantia nigra and atrophy of the tegmentum of the midbrain, internal globus pallidus and subthalamic nucleus were observed (Fig. 2b-d).

Microscopically, there was moderate to severe neuronal loss in the spinal anterior horn at all levels of the spinal cord (Fig. 3a) that relatively spares the Onufrowicz nuclei and Clarke's column. Bunina bodies were abundant in anterior horn cells (Fig. 3b). Macrophages had aggregated in the corticospinal tracts, while myelin pallor was not evident. Mild to moderate neuronal loss

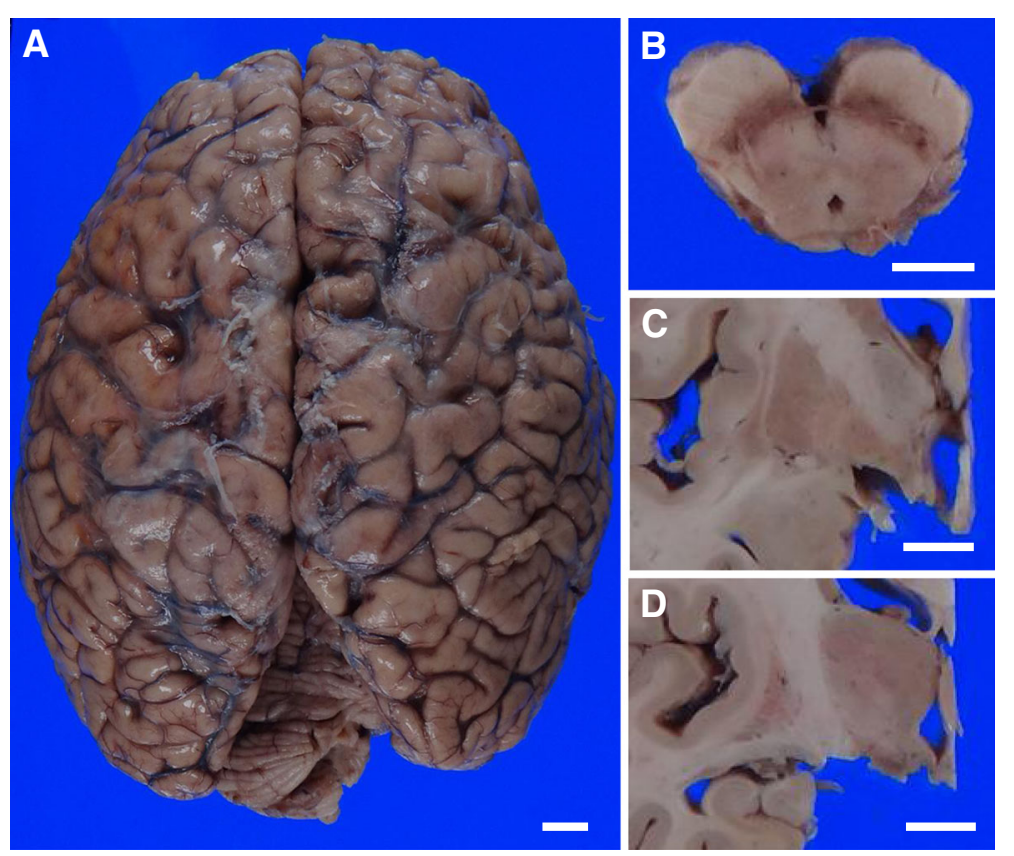

Fig. 2 Macroscopic findings. The precentral gyrus showed mild atrophy (a). Depigmentation of the substantia nigra and atrophy of the tegmentum was observed in the midbrain (b). The internal segment of the globus pallidus (c) and the subthalamic nucleus (d) were atrophied. Scale bars: $1 \mathrm{~cm}(\mathbf{a}-\mathbf{d})$ 


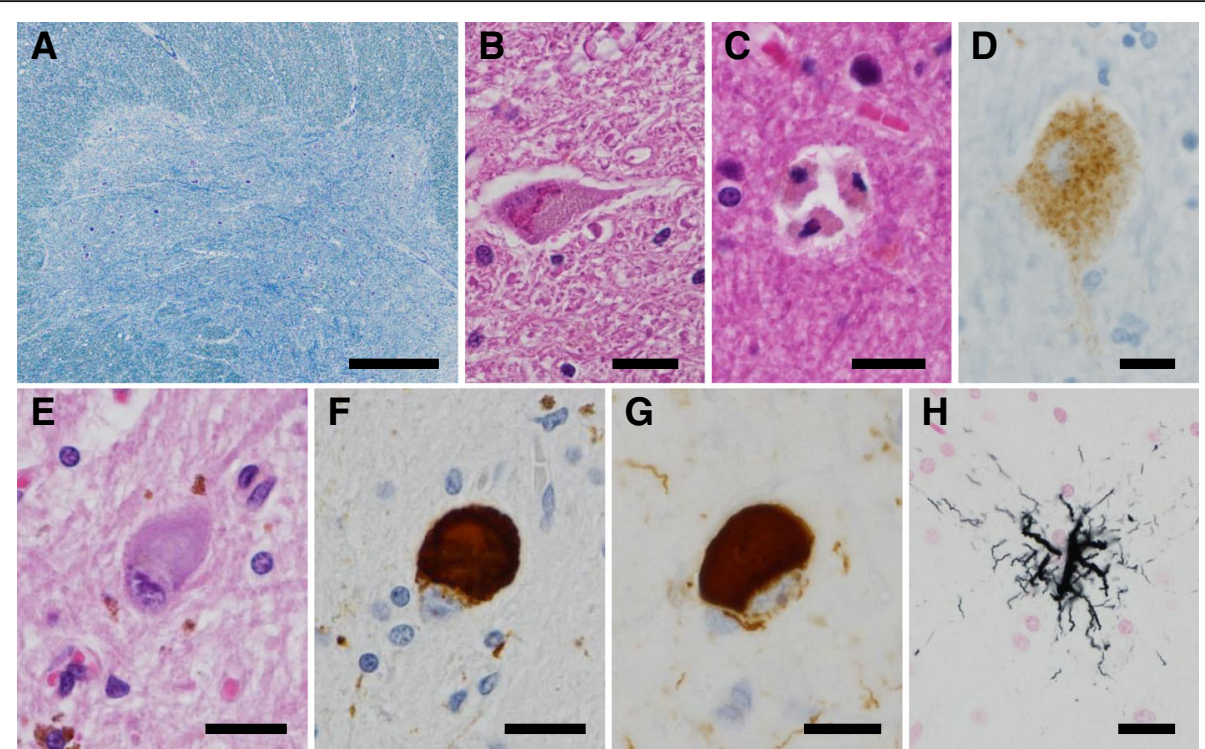

Fig. 3 Microscopic findings. The cervical spinal cord showed severe neuronal loss of anterior horn cells (a) and Bunina bodies (b). Neuronophagia was observed in the precentral gyrus (c). Phosphorylated TDP-43 neuronal cytoplasmic inclusions were present in the precental gyrus (d).

Globose-shaped neurofibrillary tangle (NFT) was detected in the substantia nigra by H-E staining (e) and immunostaining for phosphorylated tau (f) and 4-repeat tau (g). Tufted astrocytes were present in the putamen (h). Scale bars: $500 \mu \mathrm{m}(\mathbf{a}), 20 \mu \mathrm{m}$ (b-h)

and gliosis were observed in the hypoglossal nuclei. In the amygdala and area CA1 of the hippocampus, moderate to severe neuronal loss and gliosis were noted. Betz cells were mildly reduced, and some neuronophagia was observed in the precentral gyrus (Fig. 3c). On immunohistochemistry, we found that phosphorylated TDP-43immunopositive neuronal cytoplasmic inclusions ( $\mathrm{NCIs}$ ) and glial cytoplasmic inclusions (GCIs) were predominantly located in the spinal anterior horn cells, brainstem motor nuclei (including the hypoglossal, facial, and trigeminal nuclei), the precentral gyrus, and the limbic systems (including the amygdala, hippocampus, subiculum, and entorhinal cortex) (Fig. 3d).

Moreover, the substantia nigra showed marked neuronal loss with astrogliosis, melanophagia, and globoseshaped neurofibrillary tangles (NFTs) (Fig. 3e). NFTs had accumulated in the oculomotor nuclei, while neuronal loss was not obvious. Mild neuronal loss and grumose degeneration were observed in the dentate nuclei of the cerebellum. Neuronal loss and gliosis with accumulation of NFTs were observed in the subthalamic nucleus and globus pallidus. In addition, adequate amounts of NFTs and coiled bodies, immunopositive for phosphorylated tau and 4-repeat tau, were observed in PSP-vulnerable areas, including the inferior olivary nucleus, substantia nigra, subthalamic nucleus, and globus pallidus (Fig. 3f, g). These structures showed less immunoreactivity for 3-repeat tau. Tufted astrocytes were abundant in the substantia nigra, red nucleus, midbrain tectum, subthalamic nucleus, putamen, caudate nuclei, and precentral gyrus (Fig. 3h).
NFT, coiled bodies, and tufted astrocytes were also observed following Gallyas-Braak staining.

The phosphorylated TDP-43-positive structures and 4repeat tau-positive structures did not colocalize, as investigated by double immunohistochemistry in the substantia nigra or precentral gyrus. Together, these findings demonstrate the neuropathological coexistence of ALS and PSP. Only a small number of NFTs that were immunopositive for both RD4 and RD3 were detected in restricted regions, such as the transentorhinal cortex. This pathological feature was consistent with Braak NFT stage I [13] and Braak AT8 stage I [14]. No deposition of amyloid, argyrophilic grain, or $\alpha$-synuclein was detected.

Immunoblotting showed hyperphosphorylated fulllength 4-repeat tau bands (64 and $68 \mathrm{kDa})$ and C-terminal fragments $(33 \mathrm{kDa})$ in the frontal cortex (Fig. 4). This banding pattern was consistent with that previously reported in PSP $[15,16]$.

The methods used in the above analyses are provided in Additional file 2.

\section{Discussion and conclusions}

Here, we demonstrate a distinct case in which PSP and ALS coexisted clinically and pathologically. Clinically, our case corresponds to possible PSP with progressive gait freezing and probable ALS [4, 12, 17]; as in our case, variant PSP syndromes other than Richardson's often lack vertical gaze palsy [4]. Pathological investigation demonstrated neuronal loss and degeneration in the regions typically affected by PSP and ALS. We also show that 4 repeat-tau accumulation was present in 

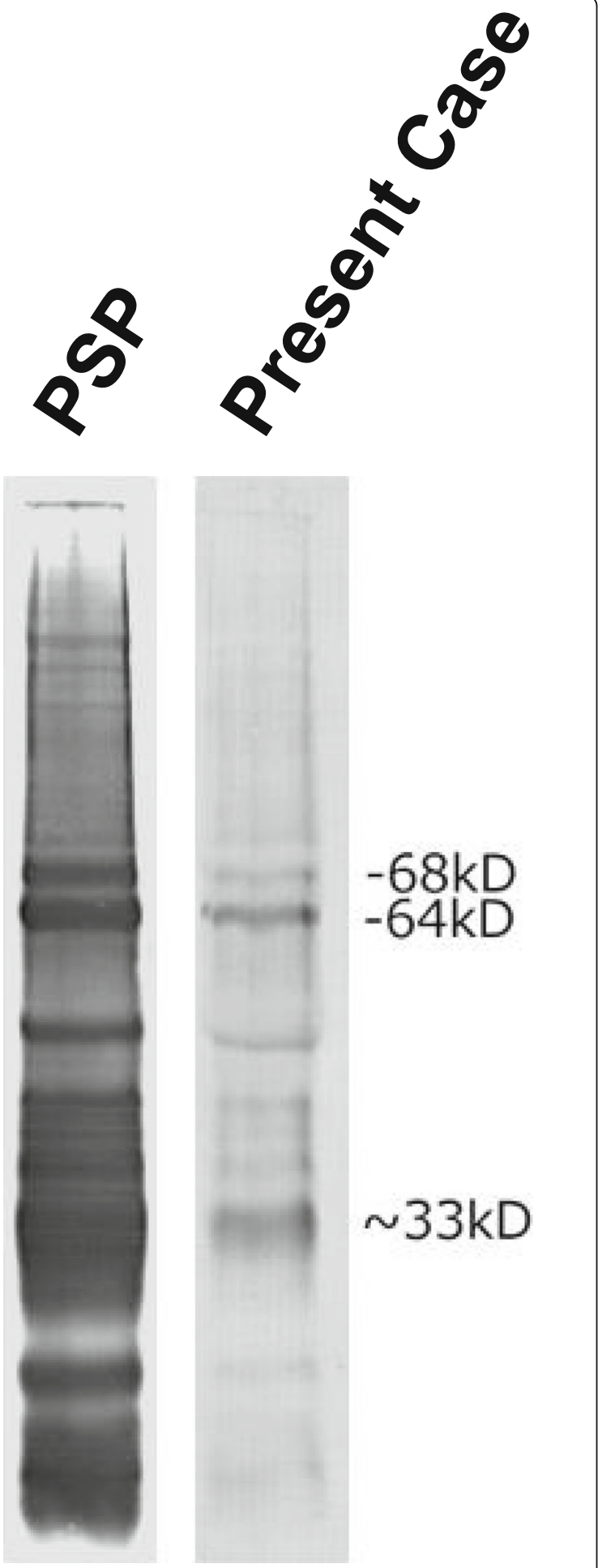

tau C
Fig. 4 Immunoblot analysis of sarkosyl-insoluble tau. Full-length hyperphosphorylated tau bands indicated by 64, $68 \mathrm{kD}$ and $\sim 33 \mathrm{kDa}$ fragments were detected, consistent with a progressive supranuclear palsy tau banding pattern

the PSP-associated regions, while TDP-43 accumulation was present in the ALS-related regions [3, 18], supporting the dual pathologies of PSP and ALS. Moreover, the biochemical findings of tau also confirmed the diagnosis of PSP and excluded corticobasal degeneration.

Given that both PSP (with Richardson's syndrome; 3.1-13.8 per 100,000 persons [19-21]) and ALS (5.010.3 per 100,000 persons [22-24]) are rare, the accidental comorbidity of PSP and ALS is highly unlikely. Rather, our case may accord with the high frequency of multiple pathologies in single cases, as revealed by recent advances in immunohistochemical methods $[25,26]$. PSP sometimes accompanies other neurodegenerative pathologies, although they do not necessarily correspond to clinical symptoms. For instance, a PSP brain is apparently accompanied by TDP-43 pathology more often than a normal aging brain $[11,26,27]$. Furthermore, there have been reports of cases with both PSP and other neurodegenerative pathologies, such as Alzheimer's disease [28, 29], Lewy body disease [30], and ballooned neurons due to argyrophilic grain disease [31]. Cases of PSP with multiple system atrophy $[32,33]$ and Pick bodies [34] have also been reported.

Conversely, tau pathology can be observed in ALS or frontotemporal lobar degeneration with TDP-43 pathology (FTLD-TDP). In one study, tau pathology of Braak NFT stage III or higher, which is apparently related to Alzheimer's pathology, was observed in over 15\% of ALS and FTLD-TDP cases [26]. In addition, co-occurrence of argyrophilic grain disease, in which phosphorylated 4-repeat tau is the pathological protein, was documented in approximately $40 \%$ of ALS cases [35]. These findings indicate that the coexistence of 3- or 4-repeat tauopathies in ALS and FTLD-TDP is not uncommon. Of further note, the comorbidity of PSP-tau and FTLD-TDP has been reported in two cases. However, these cases lacked ALS-associated symptoms, such as muscle weakness and atrophy, or pathological changes in the motor neuron system [36]. Accordingly, our case represents a unique example of the clinical and pathological comorbidity of PSP and ALS.

That being said, as PSP per se can involve mild neuronal loss and NFTs in the spinal anterior horn, which possibly present as clinical symptoms [37], one may argue that the progressive weakness observed in our case could also be attributed to PSP pathology alone. In our case, however, neuronal loss and accumulation of TDP43 inclusions were obvious in the spinal anterior horn, while NFTs and phosphorylated tau accumulation were 
scarce there. The distribution patterns of TDP-43 vs. tau pathologies were also found in the hypoglossal and facial nuclei, consistent with ALS pathology. Accordingly, the progressive weakness was likely due to the concurrent ALS pathology rather than phenotypic variation of PSP.

We note that there was little regional overlap between the ALS and PSP pathologies. Even in some regions in which both tau and TDP-43 pathologies were abundant (e.g., the precentral gyrus and substantia nigra), the severity of neuronal loss was similar to that observed in typical cases of PSP or ALS. Furthermore, we found no colocalization of 4-repeat tau and phosphorylated TDP43 on double immunohistochemistry. These findings do not support the notion that mutual exacerbation of the dual pathologies occurred in our case. That said, the cooccurrence per se may have contributed to the short duration of ALS observed in our case (5 months).

We are aware that the combination of ALS and parkinsonism is a feature of the ALS-parkinsonism-dementia complex in the Kii peninsula of Japan (Kii ALS/ PDC), in which the disease presents with NFTs of Alzheimer's type without amyloid deposition, TDP-43 pathology, and $\alpha$-synuclein pathology to varying degrees. However, the Kii ALS/PDC lacks tufted astrocytes [38], which we observed in our case. In addition, the Kii ALS/ PDC showed hyperphosphorylated tau triplet bands at 60,64 , and $68 \mathrm{kDa}$ on immunoblotting [39, 40]. Our case showed no $60 \mathrm{kDa}$ band, in contrast with the Kii ALS/PDC. Taken together, we suggest that the neuropathological findings in our case are distinct from those of the Kii ALS/PDC.

We note that genetic abnormalities can be associated with PSP, ALS, and related disorders. For instance, C9orf72 repeat expansions, which account for a large proportion of ALS and FTLD cases, are a rare genetic cause of parkinsonism, such as Parkinson's disease, corticobasal syndrome, and PSP [41]. Mutations in MAPT and GRN have also been detected in PSP, CBS, and FTLD [42], and TBK1 mutations can manifest as ALS, FTLD, or PSP [43]. Furthermore, genetic abnormalities in C9orf72 versus GRN are associated with the degree of NFT tau pathology in FTLD, suggesting a role for C9orf72 mutations in multiple proteinopathies [44]. However, in our case, the genetic studies, which included whole-exome sequencing, excluded genetic abnormalities known to be associated with these disorders.

The findings reported in our case show that distinct phenotypes, PSP and ALS, and their corresponding pathologies, including tauopathy and TDP-43 proteinopathy, can occur in a single case. Clinical symptoms distinct from those of the original syndromes, e.g., muscle atrophy and weakness in the course of atypical parkinsonism, should alert clinicians to the possibility of overlapping pathologies. It is crucial to recognize that overlapping pathologies can occur in single cases as distinct therapies become available or are being developed for distinct diseases, e.g., riluzole and edaravone for ALS and anti-tau immunotherapies for PSP. Furthermore, future clinical trials may have to consider the possibility of multiple pathologies to appropriately assess the efficacy of drug candidates.

\section{Additional files}

Additional file 1: Brain computed tomography. (PPTX $3124 \mathrm{~kb}$ )

Additional file 2: Methods. (DOCX $22 \mathrm{~kb}$ )

\section{Abbreviations}

AC-PC: Anterior commissure-posterior commissure; ALS: Amyotrophic lateral sclerosis; ALS-PDC: ALS-parkinsonism-dementia complex; FTLD-

TDP: Frontotemporal lobar degeneration with TDP-43 pathology; GCl: Glial cytoplasmic inclusion; HE: Hematoxylin-eosin; KB: Klüver-Barrera; NCl: Neuronal cytoplasmic inclusion; NFT: Neurofibrillary tangle; PLS: Primary lateral sclerosis; PSP: Progressive supranuclear palsy; TDP-43: TAR DNAbinding protein $43 \mathrm{kDa}$

\section{Acknowledgements}

The authors would like to thank Ms. Mieko Harada, Ms. Nobuko Naoi, Ms. Kyoko Okamoto, Ms. Yuki Kimura, and Ms. Sachiko Imai for providing technical assistance. English language editing was provided by Springer Nature Author Services.

\section{Authors' contributions}

$\mathrm{KF}, \mathrm{TM}$, and RM analyzed and interpreted the data and drafted and revised the manuscript. YI designed and conceptualized the study and analyzed and interpreted the data. KK, HM, and HK performed genetic analyses and interpreted the data. $\mathrm{MH}$ performed western blot analyses and interpreted the data. HS, TT, KMS, TK, HN, FU, RK, and SM analyzed and interpreted the data. All authors read and approved the final manuscript.

\section{Funding}

This work was supported by Grants-in-Aid from the Research Committee of CNS Degenerative Diseases, Research on Policy Planning and Evaluation for Rare and Intractable Diseases, Health, Labour and Welfare Sciences Research Grants, the Ministry of Health, Labour and Welfare, Japan, JSPS KAKENHI Grant Number JP 16 H06277 (SM), and AMED under Grant Number JP18dm0107103. The funding bodies did not play any role in the design of the study and collection, analysis, and interpretation of data and in writing the manuscript.

\section{Availability of data and materials}

The data that support the findings presented in this study are available from the corresponding author upon reasonable request.

\section{Ethics approval and consent to participate}

This study was approved by the institutional ethics committees of Tokushima University and Hiroshima University.

\section{Consent for publication}

Written consent to publish the clinical information was obtained from the patient's family.

\section{Competing interests}

The authors declare that they have no competing interests.

\section{Author details}

${ }^{1}$ Department of Neurology, Tokushima University Graduate School of Biomedical Sciences, 3-18-15 Kuramoto-cho, Tokushima 770-8503, Japan. ${ }^{2}$ Department of Neurology and Neuropathology (the Brain Bank for Aging Research), Tokyo Metropolitan Geriatric Hospital \& Institute of Gerontology, 35-2 Sakae-cho, Itabashi-ku, Tokyo 173-0015, Japan. ${ }^{3}$ Pressent address: PVO Japan, Patient Safety Japan, Regulatory Office Japan, Novartis Pharma K.K., 
1-23-1 Toranomon, Minayo-ku, Tokyo 105-6333, Japan. ${ }^{4}$ Department of Neurology, Sumitomo Hospital, 5-3-20 Nakanoshima, Kita-ku, Osaka 530-0005, Japan. ${ }^{5}$ Department of Epidemiology, Research Institute for Radiation Biology and Medicine, Horoshima University, 1-2-3 Kasumi, Minami-ku, Hiroshima 734-8553, Japan. ${ }^{6}$ Department of Dementia and Higher Brain Function, Tokyo Metropolitan Institute of Medical Science, 2-1-6 Kamikitazawa, Setagaya-ku, Tokyo 156-8506, Japan.

\section{Received: 17 May 2019 Accepted: 12 July 2019}

\section{Published online: 18 July 2019}

\section{References}

1. Steele JC, Richardson JC, Olszewski J. Progressive Supranuclear Palsy. A heterogeneous degeneration involving the brain stem, basal ganglia and cerebellum with vertical gaze and pseudobulbar palsy, nuchal dystonia and dementia. Arch Neurol. 1964;10:333-59.

2. Hauw JJ, Daniel SE, Dickson D, Horoupian DS, Jellinger K, Lantos PL, McKee A, Tabaton M, Litvan I. Preliminary NINDS neuropathologic criteria for Steele-Richardson-Olszewski syndrome (progressive supranuclear palsy). Neurology. 1994;44(11):2015-9.

3. Dickson DW, Rademakers R, Hutton ML. Progressive supranuclear palsy: pathology and genetics. Brain Pathol. 2007;17(1):74-82

4. Hoglinger GU, Respondek G, Stamelou M, Kurz C, Josephs KA, Lang AE, Mollenhauer B, Muller U, Nilsson C, Whitwell JL, et al. Clinical diagnosis of progressive supranuclear palsy: the movement disorder society criteria. Mov Disord. 2017:32(6):853-64.

5. Josephs KA, Katsuse O, Beccano-Kelly DA, Lin WL, Uitti RJ, Fujino Y, Boeve BF, Hutton ML, Baker MC, Dickson DW. Atypical progressive supranuclear palsy with corticospinal tract degeneration. J Neuropathol Exp Neurol. 2006;65(4):396-405.

6. Nagao S, Yokota O, Nanba R, Takata H, Haraguchi T, Ishizu H, Ikeda C, Takeda N, Oshima E, Sakane K, et al. Progressive supranuclear palsy presenting as primary lateral sclerosis but lacking parkinsonism, gaze palsy, aphasia, or dementia. J Neurol Sci. 2012;323(1-2):147-53.

7. Wakamatsu N, Yuasa T, Souma Y, Watanabe T, Miyatake T. A case of amyotrophic lateral sclerosis associated with clinical features of progressive supranuclear palsy. Rinsho Shinkeigaku. 1989;29(9):1173-5.

8. Inoue M, Kojima Y, Satoi H, Makino F, Kanda M, Shibasaki H. Case presenting both clinical features of progressive supranuclear palsy and amyotrophic lateral sclerosis. Rinsho Shinkeigaku. 2006;46(6):390-4.

9. Brigo F, Bovi T, Ferigo L, Musso A, Gambina G, Tinazzi M, Moretto G, Fiaschi A, Squintani G. Head drop in progressive supranuclear palsy: an unusual association with amyotrophic lateral sclerosis. Parkinsonism Relat Disord. 2013;19(4):467-8.

10. Rusina R, Kovacs GG, Fiala J, Hort J, Ridzon P, Holmerova I, Strobel T, Mate R. FTLD-TDP with motor neuron disease, visuospatial impairment and a progressive supranuclear palsy-like syndrome: broadening the clinical phenotype of TDP-43 proteinopathies. A report of three cases. BMC Neurol. 2011;11:50.

11. Koga S, Sanchez-Contreras M, Josephs KA, Uitti RJ, Graff-Radford N, van Gerpen JA, Cheshire WP, Wszolek ZK, Rademakers R, Dickson DW. Distribution and characteristics of transactive response DNA binding protein $43 \mathrm{kDa}$ pathology in progressive supranuclear palsy. Mov Disord. 2017;32(2):246-55.

12. Geevasinga $N$, Loy $C T$, Menon $P$, de Carvalho $M$, Swash $M$, Schrooten $M$ Van Damme P, Gawel M, Sonoo M, Higashihara M, et al. Awaji criteria improves the diagnostic sensitivity in amyotrophic lateral sclerosis: a systematic review using individual patient data. Clin Neurophysiol. 2016; 127(7):2684-91.

13. Braak H, Braak E. Neuropathological stageing of Alzheimer-related changes. Acta Neuropathol (Berl). 1991;82(4):239-59.

14. Braak H, Alafuzoff I, Arzberger T, Kretzschmar H, Del Tredici K. Staging of Alzheimer disease-associated neurofibrillary pathology using paraffin sections and immunocytochemistry. Acta Neuropathol. 2006;112(4):389-404.

15. Arai $T$, Ikeda $K$, Akiyama H, Nonaka T, Hasegawa $M$, Ishiguro K, Iritani $S$, Tsuchiya $\mathrm{K}$, Iseki $\mathrm{E}$, Yagishita $\mathrm{S}$, et al. Identification of amino-terminally cleaved tau fragments that distinguish progressive supranuclear palsy from corticobasal degeneration. Ann Neurol. 2004;55(1):72-9.

16. Taniguchi-Watanabe S, Arai T, Kametani F, Nonaka T, Masuda-Suzukake M, Tarutani A, Murayama S, Saito Y, Arima K, Yoshida M, et al. Biochemical classification of tauopathies by immunoblot, protein sequence and mass spectrometric analyses of sarkosyl-insoluble and trypsin-resistant tau. Acta Neuropathol. 2016:131(2):267-80

17. Brooks BR, Miller RG, Swash M, Munsat TL. El Escorial revisited: revised criteria for the diagnosis of amyotrophic lateral sclerosis. Amyotroph Lateral Scler Other Motor Neuron Disord. 2000;1(5):293-9.

18. Brettschneider J, Del Tredici K, Toledo JB, Robinson JL, Irwin DJ, Grossman M, Suh E, Van Deerlin VM, Wood EM, Baek Y, et al. Stages of pTDP-43 pathology in amyotrophic lateral sclerosis. Ann Neurol. 2013;74(1):20-38.

19. Hoppitt T, Pall H, Calvert M, Gill P, Yao G, Ramsay J, James G, Conduit J, Sackley C. A systematic review of the incidence and prevalence of long-term neurological conditions in the UK. Neuroepidemiology. 2011;36(1):19-28.

20. Osaki Y, Morita Y, Kuwahara T, Miyano I, Doi Y. Prevalence of Parkinson's disease and atypical parkinsonian syndromes in a rural Japanese district. Acta Neurol Scand. 2011;124(3):182-7.

21. Takigawa H, Kitayama M, Wada-Isoe K, Kowa H, Nakashima K. Prevalence of progressive supranuclear palsy in Yonago: change throughout a decade. Brain Behav. 2016:6(12):e00557.

22. Huisman MH, de Jong SW, van Doormaal PT, Weinreich SS, Schelhaas HJ, van der Kooi AJ, de Visser M, Veldink JH, van den Berg LH. Population based epidemiology of amyotrophic lateral sclerosis using capture-recapture methodology. J Neurol Neurosurg Psychiatry. 2011:82(10):1165-70.

23. Mehta P, Kaye W, Raymond J, Wu R, Larson T, Punjani R, Heller D, Cohen J, Peters T, Muravov O, et al. Prevalence of amyotrophic lateral sclerosis United States, 2014. MMWR Morb Mortal Wkly Rep. 2018;67(7):216-8.

24. Doi Y, Atsuta N, Sobue G, Morita M, Nakano I. Prevalence and incidence of amyotrophic lateral sclerosis in Japan. J Epidemiol. 2014;24(6):494-9.

25. Kapasi A, DeCarli C, Schneider JA. Impact of multiple pathologies on the threshold for clinically overt dementia. Acta Neuropathol. 2017;134(2):171-86.

26. Robinson JL, Lee EB, Xie SX, Rennert L, Suh E, Bredenberg C, Caswell C, Van Deerlin VM, Yan N, Yousef A, et al. Neurodegenerative disease concomitant proteinopathies are prevalent, age-related and APOE4-associated. Brain. 2018:141(7):2181-93.

27. Yokota O, Davidson Y, Bigio EH, Ishizu H, Terada S, Arai T, Hasegawa M, Akiyama H, Sikkink S, Pickering-Brown S, et al. Phosphorylated TDP-43 pathology and hippocampal sclerosis in progressive supranuclear palsy. Acta Neuropathol. 2010;120(1):55-66

28. Gearing M, Olson DA, Watts RL, Mirra SS. Progressive supranuclear palsy: neuropathologic and clinical heterogeneity. Neurology. 1994:44(6):1015-24.

29. Sakamoto R, Tsuchiya K, Yoshida R, Itoh Y, Furuta N, Kosuga A, Sugai Y, Mimura M. Progressive supranuclear palsy combined with Alzheimer's disease: a clinicopathological study of two autopsy cases. Neuropathology. 2009;29(3):219-29.

30. Mori H, Oda M, Komori T, Arai N, Takanashi M, Mizutani T, Hirai S, Mizuno Y. Lewy bodies in progressive supranuclear palsy. Acta Neuropathol. 2002; 104(3):273-8.

31. Togo T, Dickson DW. Ballooned neurons in progressive supranuclear palsy are usually due to concurrent argyrophilic grain disease. Acta Neuropathol. 2002;104(1):53-6.

32. Takanashi M, Ohta S, Matsuoka S, Mori H, Mizuno Y. Mixed multiple system atrophy and progressive supranuclear palsy: a clinical and pathological report of one case. Acta Neuropathol. 2002;103(1):82-7.

33. Uchikado H, DelleDonne A, Uitti R, Dickson DW. Coexistence of PSP and MSA: a case report and review of the literature. Acta Neuropathol. 2006; 111(2):186-92

34. Arima K, Murayama S, Oyanagi S, Akashi T, Inose T. Presenile dementia with progressive supranuclear palsy tangles and pick bodies: an unusual degenerative disorder involving the cerebral cortex, cerebral nuclei, and brain stem nuclei. Acta Neuropathol. 1992;84(2):128-34

35. Soma K, Fu YJ, Wakabayashi K, Onodera O, Kakita A, Takahashi H. Cooccurrence of argyrophilic grain disease in sporadic amyotrophic lateral sclerosis. Neuropathol Appl Neurobiol. 2012;38(1):54-60.

36. Storey K, Johanidesova S, Matej R, Keller J, Rohan Z, Rusina R. FTLD-TDP and progressive supranuclear palsy in comorbidity-a report of two cases with different clinical presentations. Neurocase. 2017:23(1):5-11.

37. Behrman S, Carroll JD, Janota I, Matthews WB. Progressive supranuclear palsy. Clinico-pathological study of four cases. Brain. 1969;92(3):663-78.

38. Mimuro M, Yoshida M, Kuzuhara S, Kokubo Y. Amyotrophic lateral sclerosis and parkinsonism-dementia complex of the Hohara focus of the Kii peninsula: a multiple proteinopathy? Neuropathology. 2018;38(1):98-107.

39. Kuzuhara S, Kokubo Y, Sasaki R, Narita Y, Yabana T, Hasegawa M, Iwatsubo T. Familial amyotrophic lateral sclerosis and parkinsonism-dementia complex 
of the Kii peninsula of Japan: clinical and neuropathological study and tau analysis. Ann Neurol. 2001;49(4):501-11.

40. Itoh N, Ishiguro K, Arai H, Kokubo Y, Sasaki R, Narita Y, Kuzuhara S. Biochemical and ultrastructural study of neurofibrillary tangles in amyotrophic lateral sclerosis/parkinsonism-dementia complex in the Kii peninsula of Japan. J Neuropathol Exp Neurol. 2003;62(7):791-8,

41. Lesage S, Le Ber I, Condroyer C, Broussolle E, Gabelle A, Thobois S, Pasquier F, Mondon K, Dion PA, Rochefort D, et al. C9orf72 repeat expansions are a rare genetic cause of parkinsonism. Brain. 2013;136(Pt 2):385-91.

42. Ogaki K, Li Y, Takanashi M, Ishikawa K, Kobayashi T, Nonaka T, Hasegawa M, Kishi M, Yoshino H, Funayama M, et al. Analyses of the MAPT, PGRN, and C9orf72 mutations in Japanese patients with FTLD, PSP, and CBS. Parkinsonism Relat Disord. 2013;19(1):15-20.

43. Wilke C, Baets J, De Bleecker JL, Deconinck T, Biskup S, Hayer SN, Zuchner S, Schule R, De Jonghe P, Synofzik M. Beyond ALS and FTD: the phenotypic spectrum of TBK1 mutations includes PSP-like and cerebellar phenotypes. Neurobiol Aging. 2018;62:244.e249-13.

44. Bieniek KF, Murray ME, Rutherford NJ, Castanedes-Casey M, DeJesusHernandez M, Liesinger AM, Baker MC, Boylan KB, Rademakers R, Dickson DW. Tau pathology in frontotemporal lobar degeneration with C9ORF72 hexanucleotide repeat expansion. Acta Neuropathol. 2013;125(2):289-302.

\section{Publisher's Note}

Springer Nature remains neutral with regard to jurisdictional claims in published maps and institutional affiliations.

Ready to submit your research? Choose BMC and benefit from:

- fast, convenient online submission

- thorough peer review by experienced researchers in your field

- rapid publication on acceptance

- support for research data, including large and complex data types

- gold Open Access which fosters wider collaboration and increased citations

- maximum visibility for your research: over $100 \mathrm{M}$ website views per year

At BMC, research is always in progress.

Learn more biomedcentral.com/submissions 